\title{
Risk factors associated with mortality at a milk-fed veal calf facility: A prospective cohort study
}

\author{
D. L. Renaud, T. F. Duffield, S. J. LeBlanc, S. Ferguson, D. B. Haley, and D. F. Kelton ${ }^{1}$ \\ Department of Population Medicine, University of Guelph, Ontario, Canada N1G 2W1
}

\section{ABSTRACT}

The veal industry experiences calf losses during the growing period, which represents a challenge to animal welfare and profitability. Health status at arrival may be an important predictor of calf mortality. The objectives of this prospective cohort study were to describe the health status of calves arriving at a veal farm and determine the risk factors associated with early and late mortality. Using a standardized health scoring system, calves were evaluated immediately at arrival to a commercial milk-fed veal facility in Ontario, Canada. Weight at arrival and supplier of the calf were recorded. The calves were followed until death or the end of their production cycle. Two Cox proportional hazard models were built to explore factors associated with early $(\leq 21$ $\mathrm{d}$ following arrival) and late mortality $(>21 \mathrm{~d}$ following arrival). A total of 4,825 calves were evaluated from November 2015 to September 2016. The overall mortality risk was $7 \%$, with $42 \%$ of the deaths occurring in the first $21 \mathrm{~d}$ after arrival. An abnormal navel, dehydration, housing location within the farm, arriving in the summer, and the presence of a sunken flank were associated with increased hazard of early mortality. Drover-derived calves and calves with a greater body weight at arrival had lower hazard of early mortality. Housing location within the farm, being derived from auction facilities, and an abnormal navel were associated with higher hazard of late mortality. These results demonstrate that risk factors for mortality can be identified at arrival, which represents a potential opportunity to selectively intervene on these calves to reduce mortality. However, methods of preventing the development of these conditions before arrival need to be explored and encouraged to improve the welfare of the calves entering the veal industry.

Key words: veal industry, mortality, animal welfare, health status

Received July 27, 2017.

Accepted November 15, 2017.

${ }^{1}$ Corresponding author: dkelton@uoguelph.ca

\section{INTRODUCTION}

Mortality in dairy calves, whether female or male, represents a significant welfare issue (Ortiz-Pelaez et al., 2008) and a major source of economic loss to livestock industries. High levels of antimicrobial use (Bos et al., 2013) and resistance (Catry et al., 2016) are also among the challenges faced with the rearing of dairy calves. With public concern about animal welfare on the rise (Vanhonacker et al., 2008; Spooner et al., 2014), improvements in animal health are needed to reduce the levels of morbidity and mortality.

There is a lack of published information on male calf mortality in North America; however, estimates from the veal and dairy beef industries suggest that mortality is high. Winder et al. (2016) reported a mortality risk of $8 \%$ over the entire production period at a single milk-fed facility in Ontario. Pardon et al. (2012a) reported a mortality risk of $5 \%$ on 15 Belgium milk-fed veal farms, whereas Bähler et al. (2012) reported a mortality risk of $4 \%$ in calves housed on 15 veal farms with high animal welfare standards in Switzerland. As the majority of mortality occurs within the first $3 \mathrm{wk}$ following arrival at veal calf raising facilities (Bähler et al., 2012; Pardon et al., 2012a; Winder et al., 2016), initial management at the veal facility, but also management at the dairy farm of origin, may be critical in the health and welfare of calves.

Management of newborn calves on dairy farms affects their survival and productivity, with calving management (Wells et al., 1996), colostrum management (Postema and Mol, 1984; Pardon et al., 2015), early life nutrition (Ollivett et al., 2012; Todd et al., 2017), and housing (Waltner-Toews et al., 1986; Lago et al., 2006; Windeyer et al., 2014) all playing critical roles in disease risk. Commingling, crowding, and transportation (Mormede et al., 1982; van der Fels-Klerx et al., 2000) are additional challenges faced by calves before their arrival at veal facilities.

Similarly, management practices on veal operations have been identified as risk factors affecting calf health. Purchasing practices, type of breed reared, housing, ventilation, herd size, and nutrition (Brscic et al., 2012; 
Lava et al., 2016; Todd et al., 2017) have been associated with elevated mortality, morbidity, and antimicrobial use at veal operations. Hence, management of calves on the veal operation plays an equally critical role in their health and welfare.

A management practice that is commonly used upon arrival at veal facilities is to provide group oral antibiotics (Pardon et al., 2012b), likely because of the large number of calves that enter the veal industry with health challenges (Wilson et al., 2000). However, it is unclear whether health abnormalities identified at arrival affect mortality, as the sole studies (Wilson et al., 2000; Bähler et al., 2012) evaluating individual calves at arrival yielded few associations between reduced general condition at arrival and increased risk of morbidity or mortality. If calves at high risk for mortality could be identified, it may provide an opportunity to intervene selectively with antibiotics or supportive therapy while reducing overall antibiotic use (Pardon et al., 2015).

The objectives of this study were to describe the health status of calves at arrival to a veal facility and to associate characteristics of the arriving calf with early and late mortality.

\section{MATERIALS AND METHODS}

This prospective cohort study was conducted in cooperation with a milk-fed veal producer and in accordance with the University of Guelph Animal Care Committee requirements (Animal Use Protocol: \#3453). The producer had 5 barns in different geographical locations within the southwestern region of the province of Ontario, Canada. In barns 1, 2, and 4, the calves were fed manually, whereas in barns 3 and 5 , automatic calf feeders were used. Calves were housed individually in barns 1 and 4 and in groups of 60 calves in barns 3 and 5 . Calves in barn 2 were housed in individual pens in early life, transitioning to groups of 8 calves 5 to $6 \mathrm{wk}$ following arrival.

\section{Data Collection}

When calves arrived at the barns, they were immediately evaluated according to a standardized health scoring system and weighed using a digital weigh-scale (Cardinal Scale Manufacturing Co., Webb City, MO). The supplier of the calf and receiving date were recorded. In total, there were 233 different recorded suppliers. These suppliers were divided into 7 categories (5 drovers, local, and auction). "Local" refers to dairy farmers who delivered their calves directly to the veal facility. The term "drover" was used for calves that were transported directly from multiple dairy farms to the veal facility by a third party, and "auction" was used to classify calves purchased by the veal farm from auction markets. Season was categorized as winter (December to February), spring (March to May), summer (June to August), and fall (September to November). Calves were identified at arrival based on their Canadian Cattle Identification Agency (CCIA) eartag. Trax-IT software (Merit-Trax Technologies, Mount Royal, Quebec, Canada) was used to record all mortalities occurring during the production period.

\section{Standard Health Scoring System}

An iPad (Apple Inc., Cupertino, CA) with the Calf Health Scorer app (University of Wisconsin-Madison, Madison, WI) and Qualtrics software (http://www .qualtrics.com/) was used to record the health scoring. The app provided images and descriptions to evaluate the respiratory system (nose, eye, ear, cough; McGuirk and Peek, 2014), fecal consistency (McGuirk, 2008), navel inflammation (adapted from Fecteau et al., 1997), joint swelling, and rectal temperature. A second recording form developed in Qualtrics was used to evaluate and record dehydration (adapted from Wilson et al., 2000), BCS (Wilson et al., 2000), and sunken flank (Table 1). Sunken flank (Bähler et al., 2012) was scored based on the appearance and palpation of the abdomen. A flank was not considered sunken if the calf had a convex appearance to the lower portion of the paralumbar fossa and fluid could be balloted. The health scores were not provided to the barn staff to ensure that the screening of the calves did not influence treatment decisions.

All calves were examined by 1 of 3 observers. Observer 1 , a veterinary practitioner, provided training to observers 2 and 3, who were veterinary students. Using scores gathered from all calves arriving at the facility on June 17, 2016, inter- and intraobserver agreement were calculated for observers 1 and 2 using percentage agreement (McHugh, 2012) and weighted kappa ( $\kappa$; Cohen, 1968). A Fleiss-Cohen weight type was applied when calculating the weighted $\kappa$ (Fleiss and Cohen, 1973). Observer 3 relocated to pursue another position and could not be assessed for observer agreement.

\section{Sample Size Calculation}

A proportion estimation sample size calculation was used to determine the required number of calves. Based on previous work by Winder et al. (2016) and a review of available records, we estimated that calves identified with a health abnormality at arrival would have a mortality risk of $10 \%$, whereas those without an abnormality would have a mortality risk of $7.5 \%$. Using 
DAIRY INDUSTRY TODAY

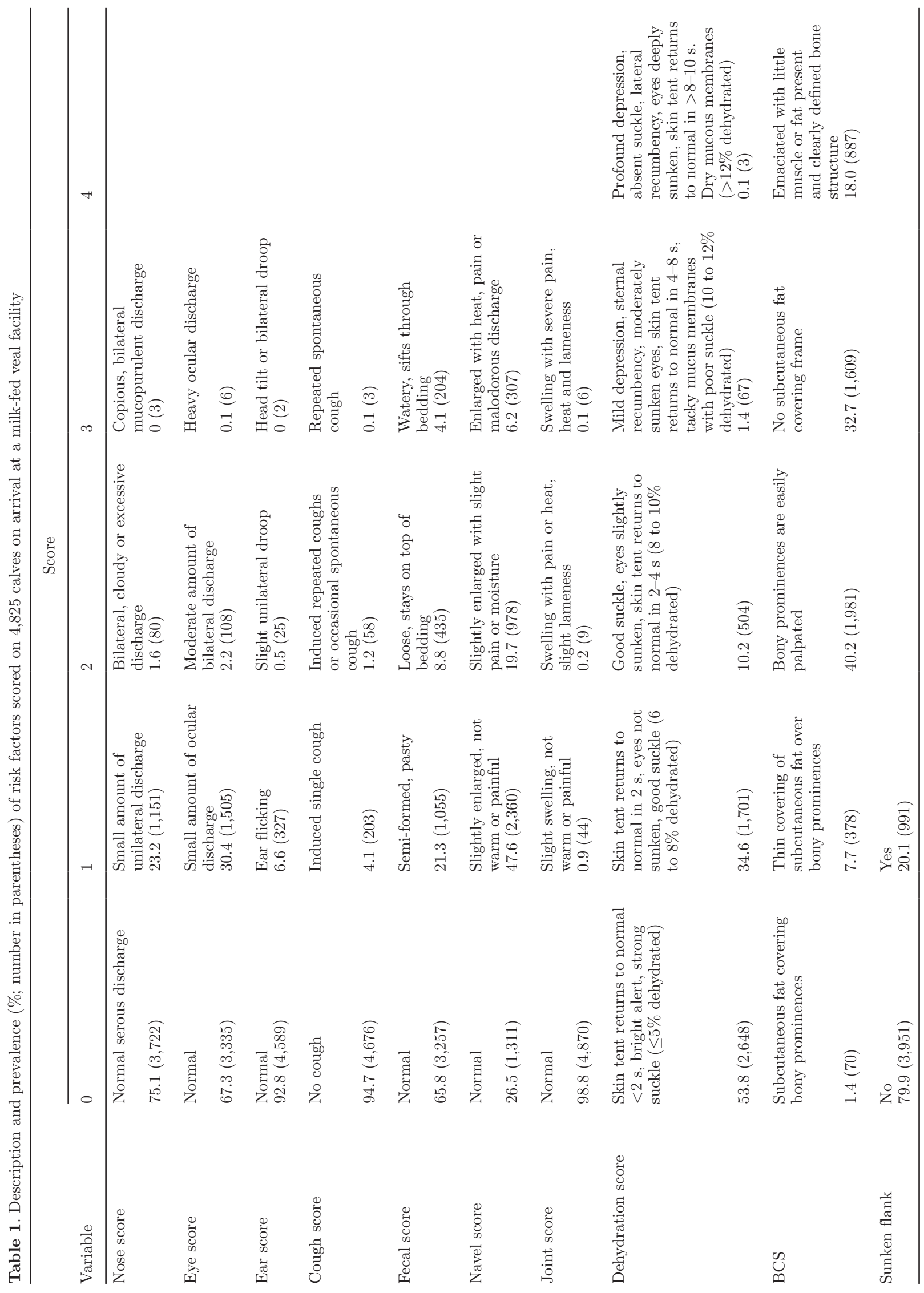




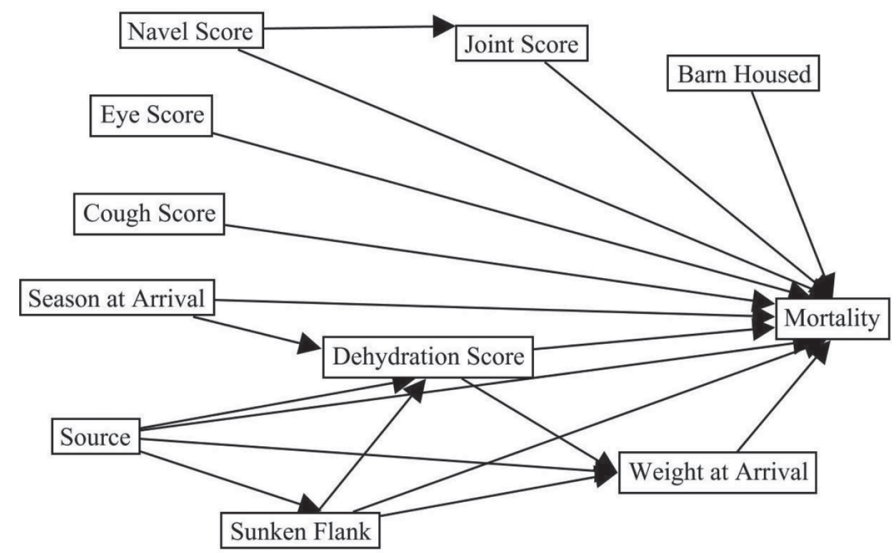

Figure 1. Causal diagram describing the relationship of measured variables to mortality occurring during the growing period at a milkfed veal calf facility in Ontario, Canada.

95\% CI and $80 \%$ power, a sample size of 4,010 calves was required.

\section{Statistical Analysis}

All statistical analyses were completed using Stata 14 (StataCorp LP, College Station, TX). Data were imported from Excel (Microsoft Corp., Redmond, WA) into Stata 14 and checked for completeness. Calves with missing data were deleted from analysis (complete-case analysis; Pigott, 2001). A causal diagram (Figure 1) was created to illustrate the hypothesized relationship between the dependent and independent variables, and was used to guide the analyses. Descriptive statistics were generated for all explanatory variables in the data set.

Two explanatory Cox proportional hazard regression models were created, one each for the outcomes early mortality and late mortality. Early mortality was defined as mortality occurring $\leq 21 \mathrm{~d}$ following arrival, and calves, if they survived, were censored at $21 \mathrm{~d}$ following arrival. Late mortality was defined as mortality occurring $>21 \mathrm{~d}$ after arrival, where calves that survived the first $21 \mathrm{~d}$ entered at $\mathrm{d} 22$ following arrival and were censored, if they survived, at the recorded date of transportation to slaughter. If the transportation to slaughter date was missing, the date was estimated from the cohort of calves that had the same arrival date. The time-series variable for both models was the number of days until mortality. The cut point of mortality at $21 \mathrm{~d}$ was selected based on previous work demonstrating that the majority of mortality occurred in the first $3 \mathrm{wk}$ after arrival at a veal calf facility (Bähler et al., 2012; Pardon et al., 2012a; Winder et al., 2016). Further rationale for the selection of this threshold was that the prevalence of morbidity also peaks in the first

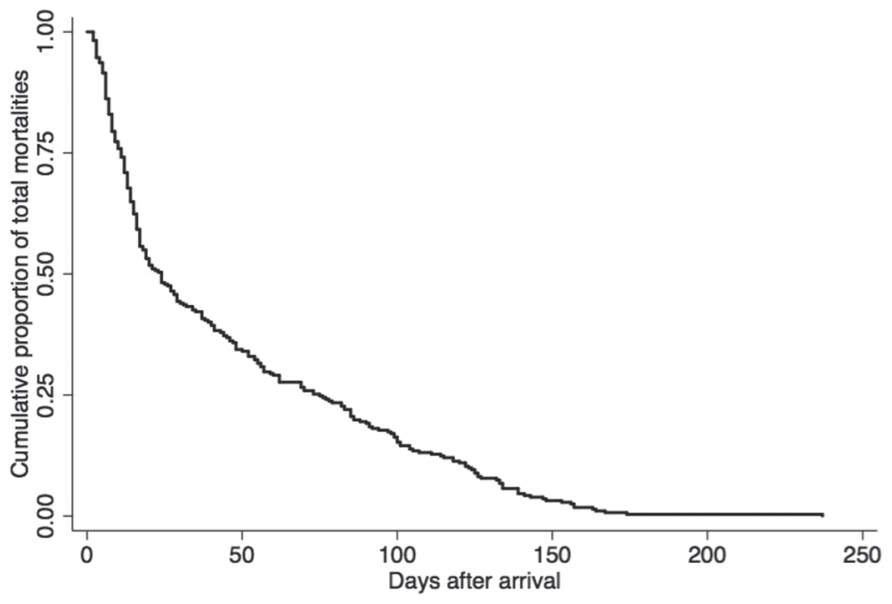

Figure 2. Kaplan-Meier survival estimate showing days after arrival at which death occurred in 347 calves screened at arrival to a milk-fed veal facility.

3 wk following arrival, and different risk factors were associated with morbidity in the first 3 wk following arrival compared with the remainder of the growing period (Brscic et al., 2012; Pardon et al., 2012a). To ensure this data set had a similar mortality pattern, a Kaplan-Meier survival estimate was created (Figure 2).

For each Cox proportional hazard model, the functional form of the continuous explanatory variables was assessed by computing the Martingale residuals from a model without the continuous predictor of interest and plotting the residuals against the predictor. If the relationship was discovered to not be linear, the variable was categorized into 2 categories. Rectal temperature in both models and BW at arrival were categorized based on cut-points generated by the Youden Index (Youden, 1950). The Youden Index is a summary measure of the receiver operator characteristic (ROC) curve, measuring the accuracy of a diagnostic marker and generating an optimal cut-point to maximize both sensitivity (Se) and specificity (Sp; Fluss et al., 2005). Collinearity among the explanatory variables was tested using Spearman rank coefficients. If the correlation coefficient between 2 variables was $\geq 0.6$, only one variable was retained, based on the fewest missing values, reliability of the measurement, and biological plausibility (Dohoo et al., 2010a). Univariable Cox proportional hazard models were constructed to screen for variables that were unconditionally associated with the outcome using a $P$-value of 0.2 . Risk factors that were associated with the outcome were subsequently offered to a multivariable model through a manual backward stepwise removal process. Variables were retained in the multivariable models if they were significant at $P<$ 0.05. Confounding was assessed by evaluating the effect of removal of a variable on the coefficients of the re- 
maining variables. A variable was deemed a confounder if it was not an intervening variable based on the causal diagram and the coefficients of a significant variable in the model changed by at least $20 \%$ when the variable was removed from the model. Two-way interactions were evaluated between variables suspected to interact based on evidence from the literature and remained in the final models if significant $(P$-value $<0.05$; Dohoo et al., 2010a). The assumption of proportionality was assessed using the test of proportional assumptions (Dohoo et al., 2010b). If the test was significant $(P<$ $0.05)$, the proportionality of each predictor was tested and the model was stratified on the nonproportional predictor. The model fit was evaluated graphically by assessing the proximity of the Cox-Snell residuals to having a unit exponential distribution (Dohoo et al., 2010b). Outliers were identified and evaluated using deviance residuals as well as score residuals. If outliers were found, they were explored to determine the characteristics of the observations that made them outliers and ensure data were not erroneous.

\section{RESULTS}

\section{Descriptive Statistics}

A total of 4,825 calves of unknown age were evaluated from November 2015 to September 2016 with $27 \%$ $(\mathrm{n}=1,280), 28 \%(\mathrm{n}=1,368), 28 \%(\mathrm{n}=1,361), 9 \%$ $(\mathrm{n}=447)$, and $8 \%(\mathrm{n}=369)$ entering barns $1,2,3$, 4 , and 5, respectively. Most calves arrived during the summer $(40 \%)$, with the fewest arriving during the fall (11\%); $30 \%$ of calves arrived in the spring and $21 \%$ of calves in winter. The majority of the calves (70\%) were drover-derived. Drovers 1, 2, 3, 4, and 5 were responsible for bringing $36,21,2,8$, and $4 \%$ of the calves evaluated, respectively. The remaining calves were delivered directly by local farmers $(18 \%)$ or purchased from auction markets $(12 \%)$. The majority of the calves that arrived were male $(99 \%)$. The females were retained in the analyses, because it is likely that they would have received similar treatment as the male calves on the source dairy farms, because the majority were freemartins. In addition, we detected no difference in early $(P=0.45)$ or late mortality $(P=0.77)$ models when comparing male and female calves in univariable analyses.

The mean arrival weight of the calves was $47 \mathrm{~kg}$ (SD: $5 \mathrm{~kg}$ ) with a range from 28 to $71 \mathrm{~kg}$. Slaughter records existed for 4,041 calves, and these calves were slaughtered for white veal after a mean growing period of $148 \mathrm{~d}$ (SD: $9 \mathrm{~d}$ ). The mean hot carcass weight of the slaughtered calves was $127 \mathrm{~kg}$ (SD: $18 \mathrm{~kg}$ ).

\section{Health Parameters}

Table 1 describes the proportion of calves with specific risk factors. Many calves entered the facility with some level of dehydration and low body condition. Of the dehydrated calves entering the facility, only $17 \%$ had diarrhea. Roughly a quarter of calves entered with an abnormal navel score (scores of 2 and 3). Very few calves had abnormal respiratory or joint scores. The mean rectal temperature was $39.2^{\circ} \mathrm{C}$, and $5 \%(\mathrm{n}=232)$ had a temperature $\geq 40^{\circ} \mathrm{C}$. Observer 1 evaluated $35 \%$ of calves, whereas observers 2 and 3 evaluated $45 \%$ and $20 \%$, respectively. Intra- and interobserver reliability were evaluated between observers 1 and 2 (Table 2). The calculated $\kappa$ statistics ranged from no to perfect agreement.

\section{Mortality}

Of the calves evaluated, 357 died (7\%), of which 148 died in the first $21 \mathrm{~d}(42 \%)$ and 209 died after the first $21 \mathrm{~d}(59 \%)$. The Kaplan-Meier survival estimate (Figure 2) demonstrated that the pattern of mortality was similar to that previously described (Bähler et al., 2012; Pardon et al., 2012a; Winder et al., 2016). Barns 1, 2, 3, 4, and 5 had a mortality risk of 8,10 ,

Table 2. Inter- and intraobserver agreement (\% and kappa score) between observers 1 and 2 for risk factors evaluated at arrival at a milk-fed veal facility $(\mathrm{n}=25$ calves $)$

\begin{tabular}{lccccc}
\hline & \multicolumn{2}{c}{ Intraobserver agreement } & & \multicolumn{2}{c}{ Interobserver agreement } \\
\cline { 2 - 3 } \cline { 5 - 6 } Variable & Agreement $(\%)$ & Weighted $\kappa^{1}$ & & Agreement (\%) & Weighted $\kappa$ \\
\hline Nose score & 97 & 0.50 & & 97 & 0.38 \\
Eye score & 97 & 0.65 & & 97 & 0.67 \\
Ear score & 100 & 1.00 & & 96 & 0.00 \\
Cough score & 94 & 0.75 & & 91 & -0.05 \\
Navel score & 95 & 1.00 & & 100 & 0.69 \\
Joint score & 100 & 0.27 & & 71 & 0.00 \\
Dehydration score & 80 & 0.53 & & 89 & 0.31 \\
BCS & 90 & &
\end{tabular}

${ }^{1}$ Calculated as described by Cohen (1968). 
Table 3. Results from a multivariable Cox proportional hazard model of early mortality $(\leq 21 \mathrm{~d}$ after arrival $)$ at the veal facility $(\mathrm{n}=4,689$ calves with 143 mortalities)

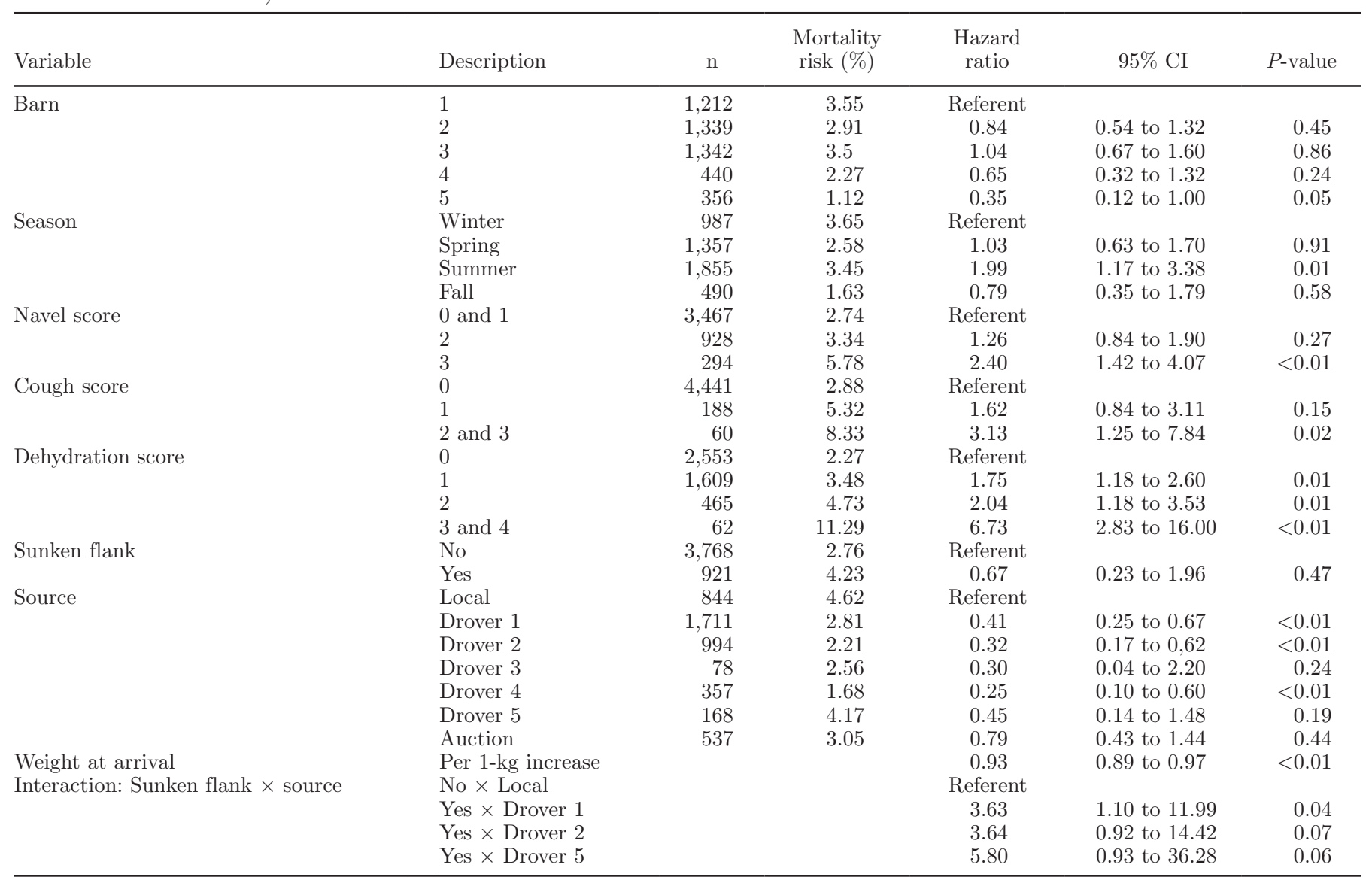

6,6 , and $5 \%$, respectively. The winter season had the highest overall mortality risk (11\%) and fall had the lowest overall mortality (4\%). Spring and summer had a mortality risks of 8 and $6 \%$, respectively.

\section{Early Mortality Model}

Based on the Youden Index, rectal temperature was cut at $39.2^{\circ} \mathrm{C}$ [Se: 0.50 ; Sp: 0.49 ; area under the curve (AUC): 0.49]. The mean time to mortality in the early mortality data set was $10.54 \mathrm{~d}$ (SD: $5.31 \mathrm{~d}$ ). The variables unconditionally associated with early mortality ( $\leq 21 \mathrm{~d}$ following arrival) were barn, season, cough score, fecal score, navel score, dehydration score, sunken flank, source, and BW (Supplemental Table S1; https://doi.org/10.3168/jds.2017-13581).

The final multivariable model contained 8 significant variables (Table 3). A navel score of 3 or elevated dehydration score was associated with higher hazard of early mortality. Drover-derived calves had a lower hazard of early mortality than locally derived calves; however, when drover-derived calves had a sunken flank, they had higher hazard of early mortality than locally derived calves without a sunken flank. Calves that weighed more on arrival also had lower hazard of early mortality.

\section{Late Mortality Model}

Based on the Youden Index, rectal temperature was cut at $39.1^{\circ} \mathrm{C}$ (Se: 0.61; Sp: 0.39; AUC: 0.50 ) and BW at arrival was cut at $48 \mathrm{~kg}$ (Se: 0.41; Sp: 0.64; AUC: 0.52). The mean time to mortality in the late mortality data set was $88.04 \mathrm{~d}$ (SD: $45.47 \mathrm{~d}$ ). The initial Cox proportional hazard model did not meet the assumption of proportional hazards, and the following models were stratified based on season at arrival. The variables that were unconditionally associated with late mortality ( $>21 \mathrm{~d}$ following arrival) were barn, nose score, eye score, cough score, navel score, and source (Supplemental Table S2; https://doi.org/10.3168/jds.2017-13581).

In the final multivariable model, 3 variables were retained (Table 4). Being housed in barn 2 and having a navel score of 3 were associated with higher hazard of late mortality. Being housed in barn 3 was associated with lower hazard of late mortality. Source of calves was 
Table 4. Results from a multivariable Cox proportional hazard model of late mortality ( $>21 \mathrm{~d}$ after arrival) at the veal facility stratified by season at arrival $(\mathrm{n}=4,610$ calves with 204 mortalities)

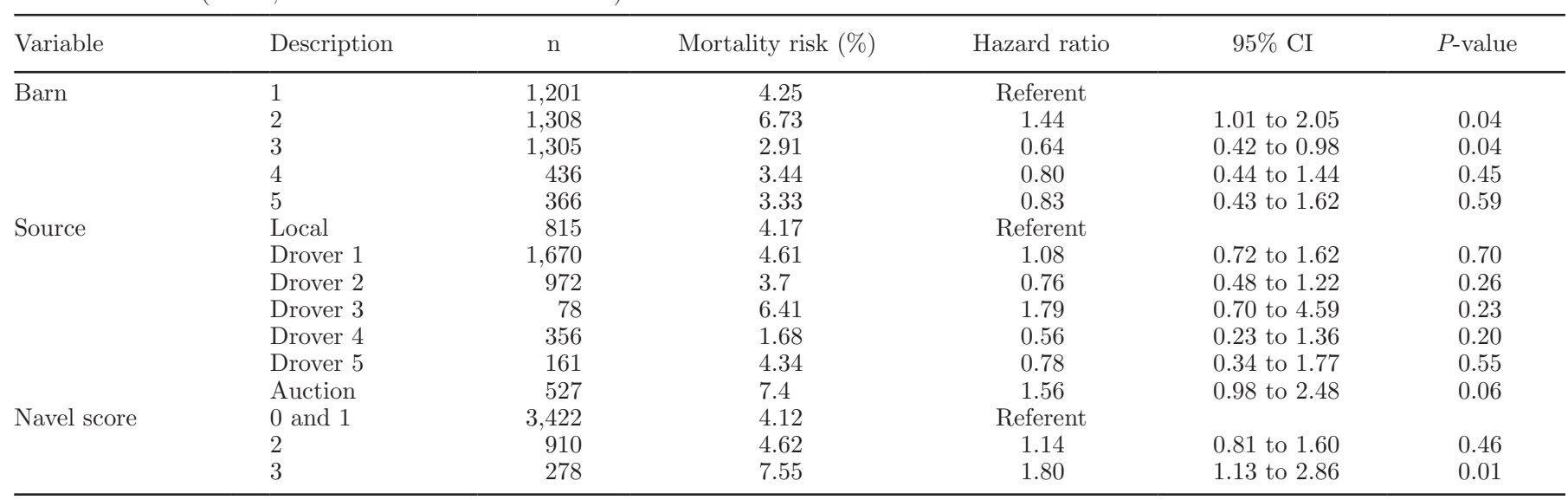

retained in the model because the overall variable had a significant $P$-value $(P=0.02)$, where calves sourced from auction facilities had a trend for a higher hazard of late mortality.

\section{DISCUSSION}

This study demonstrated that abnormal navel, very low BCS, and sunken flank were common problems found at arrival. It also identified several health variables associated with mortality at the veal facility. One of the potential limitations of this study was the subjective nature of the scoring system used and the multiple observers who scored the calves. The kappa statistics generated for ear, cough, and dehydration scores yielded slight to no agreement (Viera and Garrett, 2005) between observers 1 and 2. This is likely the result of the kappa paradox, where despite a high percentage of interobserver agreement, the corresponding value of $\kappa$ may be relatively low (Feinstein and Cicchetti, 1990) because there is little variation in the condition being evaluated. The kappa paradox may have occurred because the prevalence of those conditions was low in the group of calves scored for the calculation of $\kappa$ (Feinstein and Cicchetti, 1990; Viera and Garrett, 2005; Dohoo et al., 2010c). The small number of calves examined for the calculation of the $\kappa$ statistic (Sim and Wright, 2005) and the inability to examine the intra- and interobserver reliability for observer 3 are further limitations that need to be considered.

Navel infections have been shown to have a significant effect on mortality (Donovan et al., 1998) and the overall health of the calf (Mee, 2008). Therefore, it is not surprising that arriving at the facility with a significantly enlarged navel, with heat, pain, or malodorous discharge was associated with both early and late mortality. The prevalence of abnormal navels was similar to what has been reported in other studies evaluating male calves (Wilson et al., 2000; Bähler et al., 2012). Navel infections cause not only a localized infection but may also spread by hematogenous dissemination and affect multiple organs (Wieland et al., 2017). Antibiotic treatment of the calves with navel infections at arrival could help to reduce mortality; however, prevention on the source dairy farm would be preferable. Some preventative strategies that could be implemented at the source farm include maintaining maternity pen hygiene and ensuring adequate early intake of high-quality colostrum (Mee, 2008). In terms of navel dipping, authors have reported differences with respect to certain types of navel dip (Robinson et al., 2015; Wieland et al., 2017). However, the paucity in the available literature of studies that used a negative control group makes it difficult to support the use of navel dipping.

Severity of dehydration was a significant predictor of early mortality. Dehydration may arise from a variety of different factors, including transportation and diarrhea. Transportation of young calves long distances can lead to a measurable increase in dehydration (Knowles et al., 1997). An electrolyte feeding during transit will reduce the extent of dehydration on arrival (Knowles et al., 1999) and could reduce early mortality. However, practically, this strategy may be difficult to implement. Diarrhea may also have been responsible for creating a dehydrated state (Smith, 2009b). Correction of dehydration in calves suffering from diarrhea is important in preventing mortality (Berchtold, 2009). However, fecal score was not significant in the final multivariable model evaluating early mortality and did not interact with or confound dehydration score, so it may not influence the role that dehydration plays in early mortality. As many calves entered the facility with some degree of dehydration, measures to prevent and treat dehydration at arrival need to be explored to reduce mortality. 
The presence of a sunken flank may be an indicator of the timing of the last milk or electrolyte feeding. Drover-derived calves were likely more susceptible to early mortality when a sunken flank was detected because the combination of increased energy demands from longer transportation (Knowles et al., 1997) and little to no energy input would lead to reduced disease resistance (Chandra, 1997; Godden et al., 2005; Ollivett et al., 2012). The presence of a sunken flank was also shown by Bähler et al. (2012) to affect mortality; however, it was only significant in unconditional analysis. Thus, strategies to reduce time between meals for young calves, particularly when subjected to long transit times, could aid in reducing the risk of early mortality.

As previously demonstrated by others (Lava et al., 2016; Winder et al., 2016), barn number was associated with mortality. Brscic et al. (2012) and Lava et al. (2016) identified that housing, management, and feeding practices are risk factors that can influence calf health and need to be considered at the barn level. The barns in this study had different housing styles, barn staff, and feeding equipment, which could explain some of the variability in mortality between the different barns.

Weight at arrival affected early mortality. This finding is similar to other studies in which lower weight at arrival was associated with higher morbidity and mortality (Brscic et al., 2012; Winder et al., 2016). As previously suggested by Winder et al. (2016), weight at arrival may be a marker of age, nutrition, and weight at birth. Knowles (1995) described a strong negative correlation between age at transport and mortality. However, it is unclear whether the association with mortality is due to increased disease pressure occurring in the first weeks of life (Wells et al., 1997) or is due to transportation. The topic of age at transportation requires further exploration, as a delay in transport could be explored as a method to reduce morbidity and mortality on veal farms.

Enhanced early life nutrition increases the growth of the calf (Terre et al., 2006; Borderas et al., 2009). It also improves disease resistance (Khan et al., 2007; Ollivett et al., 2012; Todd et al., 2017) and reduces mortality (Williams et al., 1981) because more energy and protein are available to support immune function (Chandra, 1997). As heavier calves had a lower risk of early mortality, enhancing the nutrition of calves before arrival at the veal facility may provide an opportunity to improve disease resistance and lower mortality.

A surprising finding in this study was the high level of emaciation identified at arrival. This is also likely a reflection of nutritional status of the calf before arrival.
Previous disease will also reduce ADG (Virtala et al., 1996; Windeyer et al., 2014) and affect BW (Stanton et al., 2010) but could reduce BCS. With $18 \%$ of calves arriving at the facility in an emaciated state, factors affecting BCS should be explored and improved.

The source of the calves played a role in early and late mortality. Locally derived calves had higher hazard of early mortality than those from drovers, even though the drover-derived calves likely had longer transportation times. Drovers could have implemented some type of screening before agreeing to transport calves, as they are penalized monetarily for low-weight or sick calves at the veal facility. This screening would create an additional barrier of entry to the veal facility, such that calves that are ill and of low weight are not taken from the source farm, thereby reducing the odds of mortality at the veal facility. Auction-derived calves had a trend for a higher hazard of late mortality. As auction calves are exposed to at least 2 different vehicles for transportation and at least one temporary residence, where they are commingled with many other calves, it creates an opportunity for the calf to be exposed to a variety of pathogens. As the auction environment contributes to mortality caused by bovine respiratory disease in veal calves (Palechek et al., 1987) and with the majority of deaths after $21 \mathrm{~d}$ resulting from pneumonia, this may be a plausible explanation for the association. Thus, strategies used to optimize the conditions of purchase may lead to a reduction in the level of disease risk and in antimicrobial use (Lava et al., 2016).

Arrival at the facility in the summer was associated with early mortality. Higher early mortality during the summer differs from other studies evaluating female (Lombard et al., 2007; Gulliksen et al., 2009) and male calf mortality (Winder et al., 2016). However, heat stress occurring pre- and postpartum can affect immune responses in calves (Tao and Dahl, 2013; Roland et al., 2016) making them more susceptible to disease. The lack of heat dissipation strategies employed in the barns, combined with one of the hottest summers recorded in southwestern Ontario (Seglenieks, 2016), may have contributed to increased early mortality in the summer. Season at arrival did not meet the assumption of proportional hazards in the late mortality, suggesting that season has differing effects on the hazard of mortality over time, specifically during the later portion of the growing period.

The presence of induced repeated or spontaneous coughs can be used to identify calves with early respiratory disease (Poulsen and McGuirk, 2009). Coughing is an important respiratory defense mechanism that is initiated by irritation of receptors in the airways (Smith, 2009a). With repeated or spontaneous coughing being 
a hallmark clinical sign of acute or chronic respiratory disease (Andrews, 2004), interventions should be explored to reduce mortality levels.

\section{CONCLUSIONS}

The prevalence of health problems at arrival represents important risks for mortality in veal calves. Many calves at high risk for mortality can be identified upon arrival. Intervention on high-risk calves may be a strategy to reduce the risk of mortality; however, preventative measures applied before arrival to the veal facility would be a preferred approach.

\section{ACKNOWLEDGMENTS}

The authors thank the participating producer. The first author was also supported by Grober Inc. (Cambridge, ON, Canada), Veal Farmers of Ontario (Guelph, ON, Canada), Dairy Farmers of Ontario (Mississauga, ON, Canada), the Ontario Ministry of Agriculture, Food and Rural Affairs, and the Ontario Veterinary College (University of Guelph).

\section{REFERENCES}

Andrews, A. 2004. Calf respiratory disease. Pages 239-262 in Bovine Medicine. 2nd ed. Blackwell Science, Oxford, UK.

Bähler, C., A. Steiner, A. Luginbühl, A. Ewy, H. Posthaus, D. Strabel, T. Kaufmann, and G. Regula. 2012. Risk factors for death and unwanted early slaughter in Swiss veal calves kept at a specific animal welfare standard. Res. Vet. Sci. 92:162-168. https://doi .org/10.1016/j.rvsc.2010.10.009.

Berchtold, J. 2009. Treatment of calf diarrhea: Intravenous fluid therapy. Vet. Clin. North Am. Food Anim. Pract. 25:73-99. https:// doi.org/10.1016/j.cvfa.2008.10.001.

Borderas, T. F., A. M. B. de Passillé, and J. Rushen. 2009. Feeding behavior of calves fed small or large amounts of milk. J. Dairy Sci. 92:2843-2852. https://doi.org/10.3168/jds.2008-1886.

Bos, M. E., F. J. Taverne, I. M. van Geijlswijk, J. W. Mouton, D. J. Mevius, and D. J. Heederik. 2013. Consumption of antimicrobials in pigs, veal calves, and broilers in the Netherlands: Quantitative results of nationwide collection of data in 2011. PLoS One 8:e77525. https://doi.org/10.1371/journal.pone.0077525.

Brscic, M., H. Leruste, L. Heutinck, E. Bokkers, M. Wolthuis-Fillerup, N. Stockhofe, F. Gottardo, B. Lensink, G. Cozzi, and C. V. Reenen. 2012. Prevalence of respiratory disorders in veal calves and potential risk factors. J. Dairy Sci. 95:2753-2764. https://doi.org/ 10.3168/jds.2011-4699.

Catry, B., J. Dewulf, D. Maes, B. Pardon, B. Callens, M. Vanrobaeys, G. Opsomer, A. de Kruif, and F. Haesebrouck. 2016. Effect of antimicrobial consumption and production type on antibacterial resistance in the bovine respiratory and digestive tract. PLoS One 11:e0146488

Chandra, R. K. 1997. Nutrition and the immune system: An introduction. Am. J. Clin. Nutr. 66:460S-463S.

Cohen, J. 1968. Weighted kappa: Nominal scale agreement with provision for scaled disagreement or partial credit. Psychol. Bull. 70:213-220.

Dohoo, I., W. Martin, and H. Stryhn. 2010a. Model-building strategies. Pages 365-394 in Veterinary Epidemiological Research. 2nd ed. VER Inc., Charlottetown, Prince Edward Island, Canada.
Dohoo, I., W. Martin, and H. Stryhn. 2010b. Modeling survival data. Pages 467-527 in Veterinary Epidemiological Research. 2nd ed. VER Inc., Charlottetown, Prince Edward Island, Canada.

Dohoo, I., W. Martin, and H. Stryhn. 2010c. Screening and diagnostic tests. Pages 91-134 in Veterinary Epidemiological Research. 2nd ed. VER Inc., Charlottetown, Prince Edward Island, Canada.

Donovan, GA., I. Dohoo, D. Montgomery, and F. Bennett. 1998. Calf and disease factors affecting growth in female Holstein calves in Florida, USA. Prev. Vet. Med. 33:1-10. https://doi.org/10.1016/ S0167-5877(97)00059-7.

Fecteau, G., J. Pare, D. Van Metre, B. Smith, C. Holmberg, W. Guterbock, and S. Jang. 1997. Use of a clinical sepsis score for predicting bacteremia in neonatal dairy calves on a calf rearing farm. Can. Vet. J. 38:101-104.

Feinstein, A. R., and D. Cicchetti. 1990. High agreement but low Kappa: I. The problems of two paradoxes. J. Clin. Epidemiol. 43:543549. https://doi.org/10.1016/0895-4356(90)90158-L.

Fleiss, J. L., and J. Cohen. 1973. The equivalence of weighted kappa and the intraclass correlation coefficient as measures of reliability. Educ. Psychol. Meas. 33:613-619.

Fluss, R., D. Faraggi, and B. Reiser. 2005. Estimation of the Youden Index and its associated cutoff point. Biometrical J. 47:458-472. https://doi.org/10.1002/bimj.200410135.

Godden, S. M., J. Fetrow, J. Feirtag, L. Green, and S. Wells. 2005. Economic analysis of feeding pasteurized nonsaleable milk versus conventional milk replacer to dairy calves. J. Am. Vet. Med. Assoc. 226:1547-1554. https://doi.org/10.2460/javma.2005.226.1547.

Gulliksen, S. M., K. Lie, T. Løken, and O. Østerås. 2009. Calf mortality in Norwegian dairy herds. J. Dairy Sci. 92:2782-2795. https:// doi.org/10.3168/jds.2008-1807.

Khan, M. A., H. Lee, W. Lee, H. Kim, K. Ki, T. Hur, G. Suh, S. Kang, and Y. Choi. 2007. Structural growth, rumen development, and metabolic and immune responses of Holstein male calves fed milk through step-down and conventional methods. J. Dairy Sci. 90:3376-3387. https://doi.org/10.3168/jds.2007-0104.

Knowles, T. G., G. Brown, J. Edwards, A. Phillips, and P. Warriss. 1999. Effect on young calves of a one-hour feeding stop during a 19-hour road journey. Vet. Rec. 144:687-692. https://doi.org/10 $.1136 /$ vr.144.25.687.

Knowles, T. G., G. Warriss, S. Brown, J. Edwards, P. Watkins, and A. Phillips. 1997. Effects on calves less than one month old of feeding or not feeding them during road transport of up to 24 hours. Vet. Rec. 140:116-124

Knowles, T. G. 1995. A review of post-transport mortality among younger calves. Vet. Rec. 137:406-407. https://doi.org/10.1136/ vr.137.16.406.

Lago, A., S. McGuirk, T. Bennett, N. Cook, and K. Nordlund. 2006. Calf respiratory disease and pen microenvironments in naturally ventilated calf barns in winter. J. Dairy Sci. 89:4014-4025. https:// doi.org/10.3168/jds.S0022-0302(06)72445-6.

Lava, M., G. Schüpbach-Regula, A. Steiner, and M. Meylan. 2016. Antimicrobial drug use and risk factors associated with treatment incidence and mortality in Swiss veal calves reared under improved welfare conditions. Prev. Vet. Med. 126:121-130. https://doi.org/ 10.1016/j.prevetmed.2016.02.002.

Lombard, J. E., F. Garry, S. Tomlinson, and L. Garber. 2007. Impacts of dystocia on health and survival of dairy calves. J. Dairy Sci. 90:1751-1760. https://doi.org/10.3168/jds.2006-295.

McGuirk, S. M. 2008. Disease management of dairy calves and heifers. Vet. Clin. North Am. Food Anim. Pract. 24:139-153. https://doi .org/10.1016/j.cvfa.2007.10.003.

McGuirk, S. M., and S. Peek. 2014. Timely diagnosis of dairy calf respiratory disease using a standardized scoring system. Anim. Health Res. Rev. 15:145-147. https://doi.org/10.1017/ S1466252314000267.

McHugh, M. L. 2012. Interrater reliability: The kappa statistic. Biochem. Med. (Zagreb) 22:276-282.

Mee, J. F. 2008. Newborn dairy calf management. Vet. Clin. North Am. Food Anim. Pract. 24:1-17. https://doi.org/10.1016/j.cvfa .2007.10.002. 
Mormede, P., J. Soissons, R. Bluthe, J. Raoult, and G. Legarff. 1982. Effect of transportation on blood serum composition, disease incidence and production traits in young calves. Ann. Rech. Vet. 13:369-384.

Ollivett, T. L., D. Nydam, T. Linden, D. Bowman, and M. Van Amburgh. 2012. Effect of nutritional plane on health and performance in dairy calves after experimental infection with Cryptosporidium parvum. J. Am. Vet. Med. Assoc. 241:1514-1520. https://doi.org/ 10.2460/javma.241.11.1514.

Ortiz-Pelaez, A., D. Pritchard, D. Pfeiffer, E. Jones, P. Honeyman, and J. Mawdsley. 2008. Calf mortality as a welfare indicator on British cattle farms. Vet. J. 176:177-181. https://doi.org/10.1016/ j.tvjl.2007.02.006.

Palechek, N. P., M. Schoonderwoerd, and A. Perry. 1987. A case study of respiratory disease in a veal calf operation. Can. Vet. J. 28:363365.

Pardon, B., J. Alliët, R. Boone, S. Roelandt, B. Valgaeren, and P. Deprez. 2015. Prediction of respiratory disease and diarrhea in veal calves based on immunoglobulin levels and the serostatus for respiratory pathogens measured at arrival. Prev. Vet. Med. 120:169-176. https://doi.org/10.1016/j.prevetmed.2015.04.009.

Pardon, B., B. Catry, J. Dewulf, D. Persoons, M. Hostens, K. De Bleecker, and P. Deprez. 2012b. Prospective study on quantitative and qualitative antimicrobial and anti-inflammatory drug use in white veal calves. J. Antimicrob. Chemother. 67:1027-1038. https://doi.org/10.1093/jac/dkr570.

Pardon, B., K. De Bleecker, M. Hostens, J. Callens, J. Dewulf, and P. Deprez. 2012a. Longitudinal study on morbidity and mortality in white veal calves in Belgium. BMC Vet. Res. 8:26. https://doi.org/ $10.1186 / 1746-6148-8-26$

Pigott, T. D. 2001. A review of methods for missing data. Educ. Res. Eval. 7:353-383. https://doi.org/10.1076/edre.7.4.353.8937.

Postema, H. J., and J. Mol. 1984. Risk of disease in veal calves: Relationships between colostrum-management, serum immunoglobulin levels and risk of disease. Zentralbl. Veterinarmed. A 31:751-762. https://doi.org/10.1111/j.1439-0442.1984.tb01334.x.

Poulsen, K. P., and S. McGuirk. 2009. Respiratory disease of the bovine neonate. Vet. Clin. North Am. Food Anim. Pract. 25:121-137. https://doi.org/10.1016/j.cvfa.2008.10.007.

Robinson, A. L., L. L. Timms, K. J. Stalder, and H. D. Tyler. 2015 Short communication: The effect of 4 antiseptic compounds on umbilical cord healing and infection rates in the first 24 hours in dairy calves from a commercial herd. J. Dairy Sci. 98:5726-5728. https://doi.org/10.3168/jds.2014-9235.

Roland, L., M. Drillich, D. Klein-Jöbstl, and M. Iwersen. 2016. Invited review: Influence of climatic conditions on the development, performance, and health of calves. J. Dairy Sci. 99:2438-2452. https://doi.org/10.3168/jds.2015-9901

Seglenieks, F. 2016. University of Waterloo weather station annual summary-2016. Assessed Mar. 26, 2017. http://weather.uwaterloo .ca/download/historical/2016/UW_weather_station_summary 2016.pdf.

Sim, J., and C. C. Wright. 2005. The kappa statistic in reliability studies: Use, interpretation and sample size requirements. Phys. Ther. 85:257-268. https://doi.org/10.1093/ptj/85.3.257.

Smith, B. 2009a. Alterations in respiratory function. Pages 42 to 82 in Large Animal Internal Medicine. 4th ed. Elsevier, St. Louis, MO.

Smith, G. W. 2009b. Treatment of calf diarrhea: Oral fluid therapy. Vet. Clin. North Am. Food Anim. Pract. 25:55-72. https://doi .org/10.1016/j.cvfa.2008.10.006

Spooner, J. M., C. A. Schuppli, and D. Fraser. 2014. Attitudes of Canadian citizens toward farm animal welfare: A qualitative study. Livest. Sci. 163:150-158.

Stanton, A. L., D. F. Kelton, S. J. LeBlanc, S. T. Millman, J. Wormuth, R. T. Dingwell, and K. E. Leslie. 2010. The effect of treat- ment with long-acting antibiotic at postweaning movement on respiratory disease and on growth in commercial dairy calves. J. Dairy Sci. 93:574-581. https://doi.org/10.3168/jds.2009-2414.

Tao, S., and G. Dahl. 2013. Invited review: Heat stress effects during late gestation on dry cows and their calves. J. Dairy Sci. 96:40794093. https://doi.org/10.3168/jds.2012-6278.

Terre, M., M. Devant, and A. Bach. 2006. Performance and nitrogen metabolism of calves fed conventionally or following an enhancedgrowth feeding program during the preweaning period. Livest. Sci. 105:109-119. https://doi.org/10.1016/j.livsci.2006.05.001.

Todd, C. G., K. Leslie, S. Millman, V. Bielmann, N. Anderson, J. Sargeant, and T. DeVries. 2017. Clinical trial on the effects of a free-access acidified milk replacer feeding program on the health and growth of dairy replacement heifers and veal calves. J. Dairy Sci. 100:713-725. https://doi.org/10.3168/jds.2016-11401.

van der Fels-Klerx, H., H. Horst, and A. Dijkhuizen. 2000. Risk factors for bovine respiratory disease in dairy youngstock in The Netherlands: The perception of experts. Livest. Prod. Sci. 66:35-46. https://doi.org/10.1016/S0301-6226(00)00163-9.

Vanhonacker, F., W. Verbeke, E. Van Poucke, and F. Tuyttens. 2008 Do citizens and farmers interpret the concept of farm animal welfare differently? Livest. Sci. 116:126-136. https://doi.org/10.1016/ j.livsci.2007.09.017.

Viera, A. J., and J. M. Garrett. 2005. Understanding interobserver agreement: The kappa statistic. Fam. Med. 37:360-363.

Virtala, A. M. K., G. D. Mechor, Y. T. Grohn, and H. N. Erb. 1996. The effect of calf hood disease on growth of female dairy calves during the first 3 months of age in New York State. J. Dairy Sci. 79:1040-1049.

Waltner-Toews, D., S. Martin, and A. Meek. 1986. Dairy calf management, morbidity and mortality in Ontario Holstein herds. III. Association of management with morbidity. Prev. Vet. Med. 4:137158. https://doi.org/10.1016/0167-5877(86)90019-X.

Wells, S. J., D. A. Dargatz, and S. L. Ott. 1996. Factors associated with mortality to 21 days of life in dairy heifers in the United States. Prev. Vet. Med. 29:9-19. https://doi.org/10.1016/S0167 $-5877(96) 01061-6$

Wells, S. J., L. Garber, and G. Hill. 1997. Health status of preweaned dairy heifers in the United States. Prev. Vet. Med. 29:185-199. https://doi.org/10.1016/S0167-5877(96)01078-1.

Wieland, M., S. Mann, C. Guard, and D. Nydam. 2017. The influence of 3 different navel dips on calf health, growth performance, and umbilical infection assessed by clinical and ultrasonographic examination. J. Dairy Sci. 100:513-524. https://doi.org/10.3168/ jds.2016-11654.

Williams, P. E. V., D. Day, A. M. Raven, and J. A. McLean. 1981. The effect of climatic housing and level of nutrition on the performance of calves. Anim. Sci. 32:133-141. https://doi.org/10.1017/ S0003356100024910.

Wilson, L. L., J. Smith, D. Smith, D. Swanson, T. Drake, D. Wolfgang, and E. Wheeler. 2000. Characteristics of veal calves upon arrival, at 28 and 84 days, and at end of the production cycle. J. Dairy Sci. 83:843-854. https://doi.org/10.3168/jds.S0022-0302(00)74948-4.

Winder, C. B., D. Kelton, and T. Duffield. 2016. Mortality risk factors for calves entering a multi-location white veal farm in Ontario, Canada. J. Dairy Sci. 99:10174-10181. https://doi.org/10.3168/ jds.2016-11345.

Windeyer, M. C., K. Leslie, S. Godden, D. Hodgins, K. Lissemore, and S. LeBlanc. 2014. Factors associated with morbidity, mortality, and growth of dairy heifer calves up to 3 months of age. Prev. Vet. Med. 113:231-240. https://doi.org/10.1016/j.prevetmed.2013 .10 .019 .

Youden, W. J. 1950. Index for rating diagnostic tests. Cancer 3:32-35. https://doi.org/10.1002/1097-0142(1950)3:1<32::AIDCNCR2820030106>3.0.Co;2-3. 